\title{
Variables independently associated with self-reported obesity in the European Union
}

\author{
JA Martínez ${ }^{1}$, JM Kearney ${ }^{2}$, A Kafatos ${ }^{3}$, S Paquet $^{4}$ and MA Martínez-González ${ }^{1}$ \\ 'Department of Physiology and Nutrition and Public Health, University of Navarra, Pamplona, Spain: \\ ${ }^{2}$ Institute of European Food Studies, Trinity College, Dublin 2, Ireland: ${ }^{3}$ Faculty of Medicine, \\ University of Crete, Heraclion, Greece: ${ }^{4}$ Division de la Médicine Preventive Sociale, Luxembourg
}

\begin{abstract}
Objective: The rapid increase in obesity rates over recent years suggest that cultural and societal influences are affecting the adjustment in the energy balance equation in addition to other physiopathological or genetic determinants. Therefore, a pan-EU study was carried out to explore the influence of sociodemographic factors as well as some attitudes (smoking and exercise) on the prevalence of obesity in the adult population of all 15 member states of the EU.

Design: Overall, a sample of 15239 individuals aged 15 years and upwards in the EU completed the questionnaire. Subject selection was quota-controlled to make the sample nationally representative following a multistage stratified cluster sampling. Self-reported height and weight were used to calculate body mass index (BMI).

Results: From the EU average results, it can be seen that only about half of the EU population (48\%) is within the normal weight range, while the obesity (BMI $\geqslant 30 \mathrm{~kg} \mathrm{~m}^{-2}$ ) prevalence was about $10 \%$ in the EU and the overweight prevalence was 36.6\% and 25.6\% among men and women, respectively. UK subjects had the highest prevalence of obesity (12\%), while Italians, French and Swedes had the lowest levels of obesity (about 7\%). Concerning age and social class interactions, logistic regression analysis showed that high social class and younger individuals in all groups had a lower odds ratio for obesity prevalence. People with a higher level of education are less likely to be obese, while the interaction between educational levels and obesity was different for men and women. A low participation in various leisure-time physical activities, the lack of interest (precontemplation) in being involved in exercise/physical activity and the increasing number of hours sitting down at work appear to be predictors of obesity. Single individuals were less prone to become obese than couples or widowed/divorced people. Finally, smoking status was statistically linked to the prevalence of obesity, since non-smokers or ex-smokers for more than 1 year presented a higher tendency for a BMI $>30$.

Conclusions: This survey confirms that a priority area for health intervention aimed at preventing the development of obesity should be to increase levels of physical activity, although the approach will depend on the population, especially with respect to educational and socioeconomic aspects.
\end{abstract}

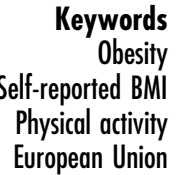

Lifestyle is increasingly being implicated in the maintenance of health and the prevalence of several chronic non-communicable diseases, including cardiovascular illnesses, diabetes and cancer ${ }^{1-3}$. In this context, obesity appears as a multifactorial condition resulting from an imbalance between energy intake and expenditure, which has been associated with reduced physical activity, as well as with the overconsumption of fat-rich and high-energy-yielding foods ${ }^{4}$. The rapid increase in obesity rates over recent years suggests that cultural and societal influences are affecting the adjustment in the energy balance equation in addition to other physiopathological or genetic determinants ${ }^{5,6}$.
The process of modernization, urbanization and changes in world trade in both developing and developed countries has brought about a number of consequences affecting nutritional and physical activity patterns that contribute to the development of obesity $^{7}$. Thus, the food system has improved the nutritional quality of diets and the availability of nutrients, while the sedentary lifestyle with motorized transport and many labour-saving devices as well as other physically inactive pursuits (TV viewing, computer work, etc.) have risen over the last few decades $^{8,9}$. Therefore, dietary and physical activity patterns are considered to be two major modifiable 
factors explaining excessive weight for height, which may be important in the development of different prevention strategies at different levels: universal (directed to everybody), selective (high risk groups) or targeted (directed to those with weight problems) ${ }^{10,11}$.

Thus, an effective management of the obesity 'epidemic' needs to establish social, cultural, economic, educational and other environmental factors involved in the weight status of the community or populations in order to develop programmes and action protocols as well as other interventions to prevent excessive weight gain and other related diseases ${ }^{12,13}$. Additionally, interventions on epidemiological predictors of obesity may produce significant benefits concerning behavioural and psychological correlates of quality of life such as self-esteem and interpersonal relations ${ }^{14,15}$.

In this context, attitudinal surveys need to be performed to inform national and international policy makers, public health specialists and scientists in the fields of food and nutrition in order to develop specifically targeted campaigns and comprehensive health strategies for the prevention and management of obesity $^{7,16}$. Therefore, a pan-EU study was carried out to explore the influence of sociodemographic factors as well as some attitudes (towards smoking and exercise) on the prevalence of obesity in the adult population of all 15 member states of the EU.

\section{Methods}

A questionnaire on attitudes to physical activity/ exercise, body weight and health was developed by the Institute of European Food Studies (IEFS), which was supervised by a project management group composed of experts in the field of physical activity/ exercise and obesity, market researchers from industry, and representatives from each of the 15 member states in the $\mathrm{EU}^{17}$.

One of the objectives of the survey was to determine the proportion and sociodemographic characteristics of the obese population (self-reported) and the attitudes about exercise of people suffering from obesity in the EU. All subjects were asked about their weight and height, as well as about their participation in various physical activities/sport in their leisure time, their attitudes towards exercise/physical activity and the hours they spent sitting down at work, as well as a question on smoking status. The final questionnaire, which included 12 close-ended questions, was translated from the English version into all relevant languages and was verified by the Project Management Group by performing a pilot survey on 20 subjects in each member state to ensure that the original meaning had been maintained.

Subjects were selected and interviewed by fieldworkers belonging to a market research organization
'Eurobus' (Taylor-Nelson), which is an international group of research organizations offering market research in each member state for conducting crosscountry surveys. An omnibus approach was used, in which subjects answered questions on different topics from various clients in a single session. Each subject was personally contacted at his/her home by a professional interviewer specifically trained for this study. The interviews were completed between March and April 1997 with an average duration of 15 minutes. All research organizations in the present survey conformed to the standards of marketing research set out by ICC/ESOMAR ${ }^{18}$.

The survey collected information about gender, age, income of the head of the household, highest level of education and marital status. Single, married/ cohabiting and divorced/widowed were the categories for marital status, while age was distributed into four levels: $15-24,25-44,45-64$ and +65 years old. Education level was classified into three categories: primary, secondary and tertiary level reached; while social class was standardized as high, medium and low (ABC1, C2 and DE). In some EU member states social class was defined by level of income while in others it was defined by occupation.

Subjects were asked to report their own height and weight which were used to calculate the BMI $\left(\mathrm{kg} \mathrm{m}^{-2}\right)$ in order to estimate the extent of underweight, normal weight, overweight and obese populations throughout the EU. In this report, BMI was classified as follows 5 : underweight $\leqslant 19.99$, normal weight $20-24.99$, overweight 25-29.99 and obese $\geqslant 30$. Apart from having a picture of the proportions of overweight and obese people in the different member states and among different sociodemographic groups, the attitudes to physical activity (precontemplation status or involvement in sports) as well as inactivity levels among the different body weight groups through self-reported sitting down hours at work (more than 6 hours, which represents the 75th or over percentile) were assessed $^{19,20}$. Precontemplation was defined as an attitude stage in which no changes are being considered concerning physical activity ${ }^{19}$.

The national samples were weighted according to the proportional size of the population of each country. Furthermore, subject selection was quota-controlled to make the sample nationally representative by various sociodemographic factors based on the most recent official statistics (census data) in each member state. With these criteria and, once individuals who did not want to participate were excluded, approximately 1000 adults aged 15 years and upwards, from each member state were selected to complete the interview-assisted face-to-face questionnaire (in Luxembourg 500 subjects were selected, in Germany 1250 were selected, in the UK 1250 were selected of which 250 were from 
Northern Ireland). Overall, 15239 subjects completed the questionnaire.

A multivariable logistic regression model was fitted to assess factors related to obesity ${ }^{21}$. The variables independently associated with obesity (BMI $>30 \mathrm{~kg} \mathrm{~m}^{-2}$ ) versus normal or underweight individuals (BMI $<25 \mathrm{~kg} \mathrm{~m}^{-2}$ ) which were analysed included age, social class, sex, education, marital or smoking status and physical activity. Given that the dependent variable was dichotomous, we used a logistic regression model to produce adjusted odds ratios (OR) as a measure of association to estimate relative risks. The adjusted OR with their respective 95\% confidence intervals were calculated. Young, male, high social class, single and non-smokers were chosen as the categories of reference for the independent variables.

\section{Results}

From the EU average results, it can be noted that almost half of the EU population is within the normal weight range (men $48.6 \%$, women $47.9 \%$ ), while the remaining were underweight (men $6.0 \%$, women $16.3 \%$ ), overweight (men 36.6\%, women 25.6\%) or obese (men $9.0 \%$, women $10.1 \%$ ). The geographical distribution (Fig. 1) showed that the UK has the highest prevalence of obesity (12\%), while the Italians, French and Swedes have the lowest levels of obesity (about 7\%). Spain, Germany and Greece were the countries with a higher combined prevalence of obese and overweight people when men and women were considered together. Austria, Spain, the UK and Belgium exhibited the highest prevalence of obesity among men, whereas Greece and the UK showed the greatest prevalence among women.

The percentage of overweight and obese individuals among EU males and females varies with age, socioeconomic factors and education levels as well as depending on marital and smoking status (Tables 1 and 2). Among males, the highest prevalence of overweight was found in those aged 45-54 years with primary education and in those aged $65+$ years with tertiary education. For all education levels, obesity was more prevalent among the older age group, particularly amongst those with a low level of education. A strong association between levels of obesity and education was apparent, with 55-65-year-old primary-educated females having four times the level of obesity of females with tertiary education in the same age group.

Odds ratios for prevalence of obesity rose steeply with increasing age, especially for the lower social class, up to 45-64 years and declined for those over 65 years for all social classes (Fig. 2). The highest OR was observed for 45-64-year-olds of low social class; OR

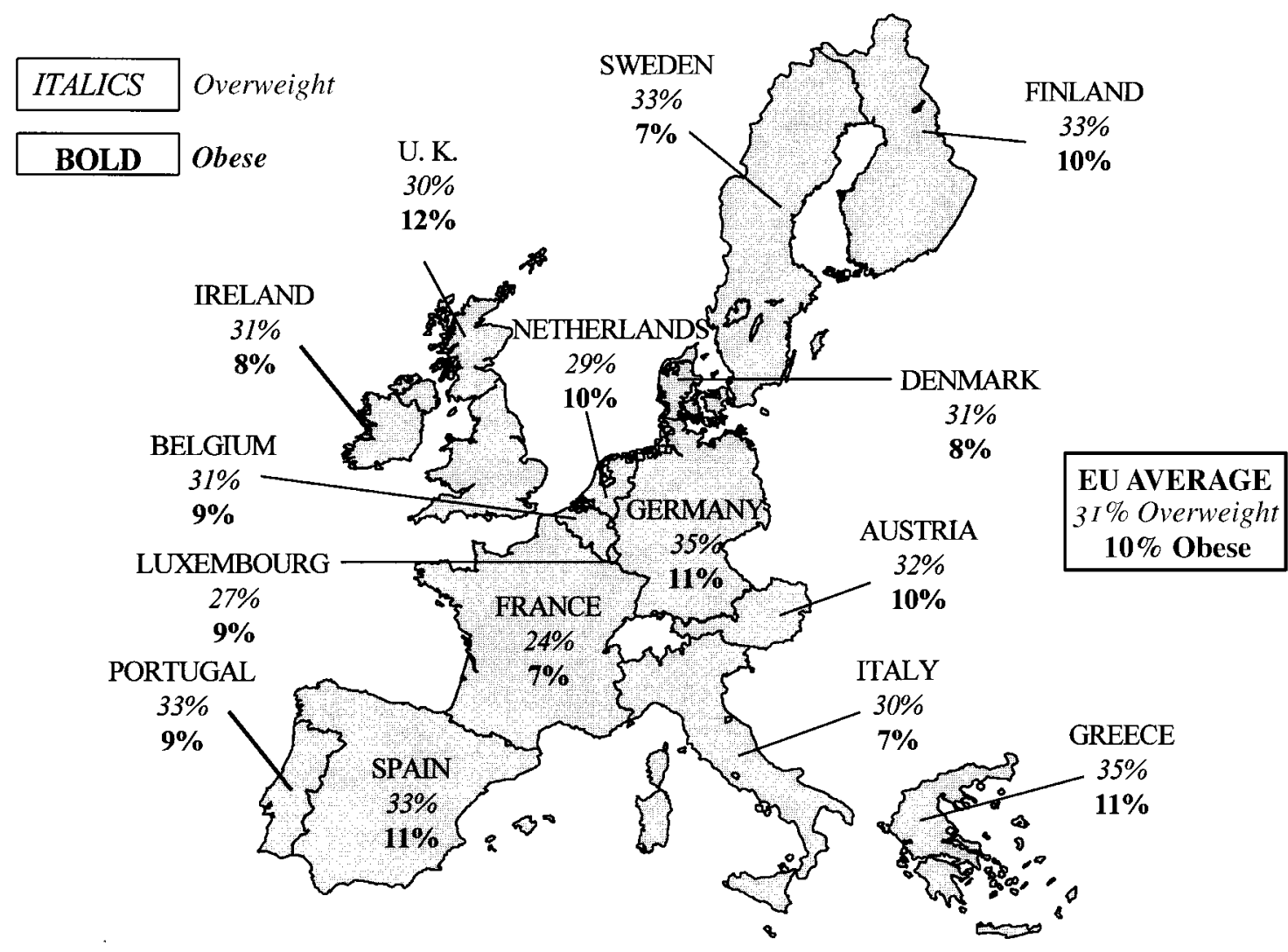

Fig. 1 Geographical distribution of the prevalence of overweight and obese people in the 15 member states of the EU 
Table 1 Distribution of BMI $\left(\mathrm{kg} \mathrm{m}^{-2}\right)$ and prevalence $(\%)$ of overweight and obese people* in the EU $(n=15239)$ classified by selected sociodemographic, behavioural and attitudinal factors

\begin{tabular}{|c|c|c|c|c|c|c|}
\hline & \multicolumn{2}{|c|}{ Mean BMI } & \multicolumn{2}{|c|}{ Overweight (\%) } & \multicolumn{2}{|c|}{ Obesity (\%) } \\
\hline & Men & Women & Men & Women & Men & Women \\
\hline $\begin{array}{l}\text { Age (years) } \\
15-24 \\
25-34 \\
35-44 \\
45-54 \\
55-64 \\
65+\end{array}$ & $\begin{array}{l}22.6 \\
24.5 \\
25.4 \\
26.1 \\
26.2 \\
25.9\end{array}$ & $\begin{array}{l}21.6 \\
23.2 \\
24.1 \\
25.2 \\
26.1 \\
25.5\end{array}$ & $\begin{array}{l}15.0 \\
30.4 \\
43.0 \\
41.5 \\
47.7 \\
48.0\end{array}$ & $\begin{array}{l}10.7 \\
18.8 \\
23.6 \\
31.8 \\
39.8 \\
38.3\end{array}$ & $\begin{array}{r}2.5 \\
6.3 \\
8.6 \\
14.1 \\
13.4 \\
10.9\end{array}$ & $\begin{array}{r}2.3 \\
6.6 \\
9.0 \\
12.9 \\
17.3 \\
13.7\end{array}$ \\
\hline $\begin{array}{l}\text { Socioeconomic level } \\
\text { Lower } \\
\text { Middle-lower } \\
\text { Middle } \\
\text { Middle-upper }\end{array}$ & $\begin{array}{l}25.0 \\
25.1 \\
25.0 \\
24.6\end{array}$ & $\begin{array}{l}23.2 \\
23.6 \\
24.7 \\
25.0\end{array}$ & $\begin{array}{l}33.4 \\
38.4 \\
38.2 \\
32.2\end{array}$ & $\begin{array}{l}31.3 \\
28.5 \\
22.2 \\
19.9\end{array}$ & $\begin{array}{r}11.1 \\
8.9 \\
8.0 \\
7.8\end{array}$ & $\begin{array}{r}13.8 \\
12.6 \\
8.0 \\
5.6\end{array}$ \\
\hline $\begin{array}{l}\text { Education level } \\
\text { Primary } \\
\text { Secondary } \\
\text { Tertiary }\end{array}$ & $\begin{array}{l}25.5 \\
24.9 \\
24.5\end{array}$ & $\begin{array}{l}25.5 \\
23.8 \\
22.8\end{array}$ & $\begin{array}{l}43.8 \\
34.6 \\
31.5\end{array}$ & $\begin{array}{l}37.0 \\
22.1 \\
15.4\end{array}$ & $\begin{array}{r}12.1 \\
8.4 \\
5.9\end{array}$ & $\begin{array}{r}15.9 \\
8.5 \\
4.4\end{array}$ \\
\hline $\begin{array}{l}\text { Marital status } \\
\text { Single } \\
\text { Married } \\
\text { Widowed/divorced/separated }\end{array}$ & $\begin{array}{l}23.8 \\
25.7 \\
25.3\end{array}$ & $\begin{array}{l}22.8 \\
24.6 \\
25.1\end{array}$ & $\begin{array}{l}25.9 \\
43.6 \\
37.0\end{array}$ & $\begin{array}{l}17.5 \\
29.0 \\
29.9\end{array}$ & $\begin{array}{r}6.6 \\
10.2 \\
11.4\end{array}$ & $\begin{array}{r}5.8 \\
11.4 \\
14.1\end{array}$ \\
\hline $\begin{array}{l}\text { Smoking status } \\
\text { Current } \\
\text { Never } \\
\text { Ex }(<1 \text { year }) \\
\text { Ex }(>1 \text { year })\end{array}$ & $\begin{array}{l}24.6 \\
24.9 \\
25.7 \\
26.3\end{array}$ & $\begin{array}{l}23.5 \\
24.5 \\
23.2 \\
24.7\end{array}$ & $\begin{array}{l}32.7 \\
36.7 \\
43.1 \\
47.3\end{array}$ & $\begin{array}{l}20.7 \\
28.1 \\
17.8 \\
27.6\end{array}$ & $\begin{array}{r}7.5 \\
8.6 \\
7.9 \\
14.9\end{array}$ & $\begin{array}{r}6.9 \\
11.8 \\
5.7 \\
11.9\end{array}$ \\
\hline $\begin{array}{l}\text { Attitude towards activity } \\
\text { Precontemplation }\end{array}$ & 25.6 & 24.8 & 40.7 & 31.1 & 12.5 & 13.0 \\
\hline Total & 25.0 & 24.1 & 36.6 & 25.6 & 9.0 & 10.1 \\
\hline
\end{tabular}

*Overweight, $25-29.9 \mathrm{~kg} \mathrm{~m}^{-2}$; obesity, $\geqslant 30 \mathrm{~kg} \mathrm{~m}^{-2}$.

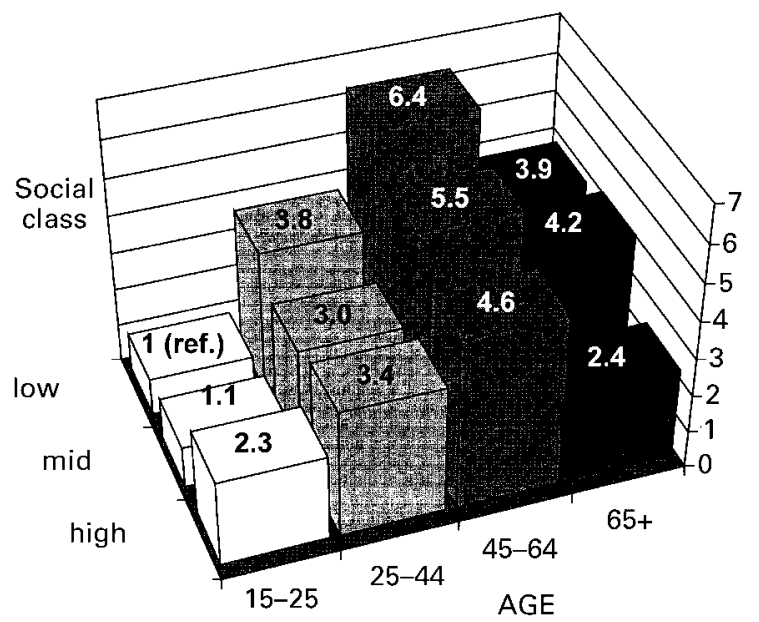

Fig. 2 Joint classification of the sample according to age (15-24, $25-44,45-64$ and $\geqslant 65$ years) in the frontal axis and social class (low, lower or middle-lower; mid, middle; high, middle-upper) in the lateral axis. For each combination of age and social class the adjusted prevalence odds ratio for obesity (BMI $\geqslant 30 \mathrm{~kg} \mathrm{~m}^{-2}$ ) is presented with reference to the category of younger ages and lower social class for prevalence of obesity increased with decreasing educational level, especially in females (Fig. 3).

The information about marital status reveals that single individuals were less prone to be obese than couples or widowed/divorced people (Table 2). Smoking status was statistically linked to the prevalence of

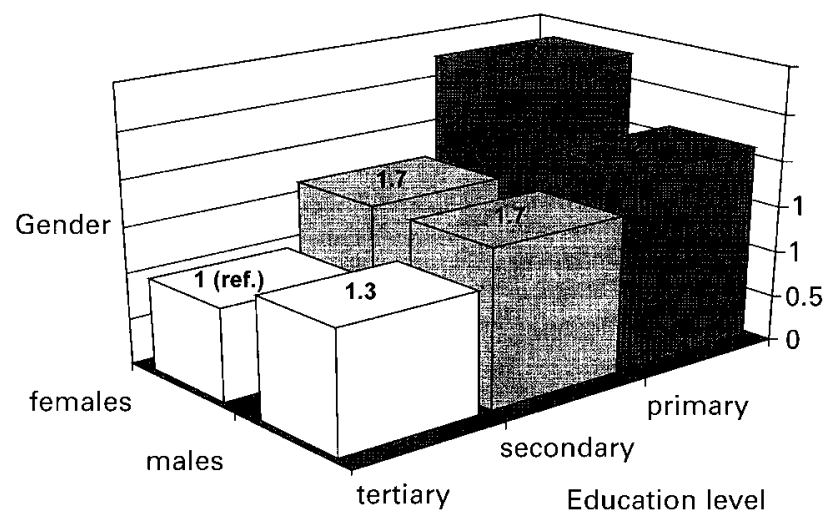

Fig. 3 Joint classification of the sample according to educational level (tertiary, secondary or primary level) in the frontal axis and gender in the lateral axis. For each group of education and gender the adjusted prevalence odds ratio for obesity $\left(\mathrm{BMI} \geqslant 30 \mathrm{~kg} \mathrm{~m}^{-2}\right)$ is presented with reference to the category of women with tertiary educational level 
Table 2 Odds ratios (OR) with their respective 95\% confidence intervals $(95 \% \mathrm{Cl})$ for the prevalence of obesity ${ }^{*}$ in the EU (men and women analysed together) using logistic regression analyses

\begin{tabular}{|c|c|c|c|c|c|c|}
\hline & \multicolumn{2}{|c|}{ Crude } & \multicolumn{2}{|c|}{$\begin{array}{l}\text { Adjusted by age and } \\
\text { gendert }\end{array}$} & \multicolumn{2}{|c|}{ Multivariate adjusted $\ddagger$} \\
\hline & OR & $95 \% \mathrm{Cl}$ & OR & $95 \% \mathrm{Cl}$ & OR & $95 \% \mathrm{Cl}$ \\
\hline Sex (women vs. men) & 1.12 & $1.00-1.25$ & 1.10 & $0.98-1.23$ & 1.08 & $0.96-1.22$ \\
\hline $\begin{array}{l}\text { Age (years) } \\
15-24 \text { (reference) } \\
25-34 \\
35-44 \\
45-54 \\
55-64 \\
65+\end{array}$ & $\begin{array}{l}1 \\
2.76 \\
3.89 \\
6.23 \\
7.31 \\
5.68\end{array}$ & $\begin{array}{l}2.07-3.68 \\
2.94-5.15 \\
4.73-8.20 \\
5.55-9.64 \\
4.27-7.56\end{array}$ & $\begin{array}{l}2.75 \\
3.87 \\
6.20 \\
7.31 \\
5.67\end{array}$ & $\begin{array}{l}2.06-3.67 \\
2.92-5.13 \\
4.71-8.16 \\
5.54-9.63 \\
4.27-7.54\end{array}$ & $\begin{array}{l}2.57 \\
3.36 \\
4.95 \\
4.91 \\
3.06\end{array}$ & $\begin{array}{l}1.88-3.52 \\
2.46-4.60 \\
3.63-6.76 \\
3.58-6.73 \\
2.20-4.26\end{array}$ \\
\hline $\begin{array}{l}\text { Socioeconomic level } \\
\text { Middle-upper (reference) } \\
\text { Middle } \\
\text { Middle-lower } \\
\text { Lower }\end{array}$ & $\begin{array}{l}1 \\
1.05 \\
1.41 \\
1.65\end{array}$ & $\begin{array}{l}0.87-1.21 \\
1.18-1.69 \\
1.37-1.99\end{array}$ & $\begin{array}{l}1.04 \\
1.38 \\
1.56\end{array}$ & $\begin{array}{l}0.86-1.27 \\
1.15-1.66 \\
1.28-1.89\end{array}$ & $\begin{array}{l}1.03 \\
1.16 \\
1.24\end{array}$ & $\begin{array}{l}0.84-1.27 \\
0.95-1.43 \\
0.99-1.55\end{array}$ \\
\hline $\begin{array}{l}\text { Education level } \\
\text { Tertiary (reference) } \\
\text { Secondary } \\
\text { Primary }\end{array}$ & $\begin{array}{l}1 \\
1.56 \\
2.66\end{array}$ & $\begin{array}{l}1.29-1.88 \\
2.21-3.22\end{array}$ & $\begin{array}{l}1.54 \\
2.12\end{array}$ & $\begin{array}{l}1.28-1.86 \\
1.75-2.58\end{array}$ & $\begin{array}{l}1.48 \\
2.17\end{array}$ & $\begin{array}{l}1.20-1.81 \\
1.73-2.74\end{array}$ \\
\hline $\begin{array}{l}\text { Marital status } \\
\text { Single (reference) } \\
\text { Married } \\
\text { Widowed/divorced/separated }\end{array}$ & $\begin{array}{l}1 \\
1.95 \\
2.23\end{array}$ & $\begin{array}{l}1.70-2.24 \\
1.49-3.32\end{array}$ & $\begin{array}{l}1.13 \\
1.07\end{array}$ & $\begin{array}{l}0.97-1.31 \\
0.87-1.32\end{array}$ & $\begin{array}{l}1.23 \\
1.05\end{array}$ & $\begin{array}{l}1.03-1.46 \\
0.83-1.31\end{array}$ \\
\hline $\begin{array}{l}\text { Smoking status } \\
\text { Never (reference) } \\
\text { Current } \\
\text { Ex }(<1 \text { year }) \\
\text { Ex }(>1 \text { year })\end{array}$ & $\begin{array}{l}1 \\
0.71 \\
0.73 \\
1.41\end{array}$ & $\begin{array}{l}0.63-0.81 \\
0.48-1.10 \\
1.20-1.66\end{array}$ & $\begin{array}{l}0.76 \\
0.82 \\
1.19\end{array}$ & $\begin{array}{l}0.67-0.87 \\
0.54-1.24 \\
1.01-1.40\end{array}$ & $\begin{array}{l}0.67 \\
0.84 \\
1.23\end{array}$ & $\begin{array}{l}0.58-0.78 \\
0.55-1.29 \\
1.03-1.46\end{array}$ \\
\hline
\end{tabular}

${ }^{*} \mathrm{BMI} \geqslant 30 \mathrm{~kg} \mathrm{~m}^{-2}$.

†The OR for the comparison between women and men was adjusted by age, and the OR for the strata of age was adjusted by sex.

$\ddagger$ In addition to all the variables which are shown in the table, the logistic regression model was also adjusted by time spent sitting down per week (as a continuous variable), participation in leisure-time physical activity (yes/no) and country (15 levels corresponding to the 15 member states).

obesity, since smokers or ex-smokers for more than 1 year presented a higher tendency to have a BMI $\geqslant 30$ (Table 2). A low participation in sport activities, a lack of interest in being involved in exercise/physical activity (precontemplation) and an increasing number of hours sitting down at work appeared to be statistically significant predictors of obesity (Fig. 4).

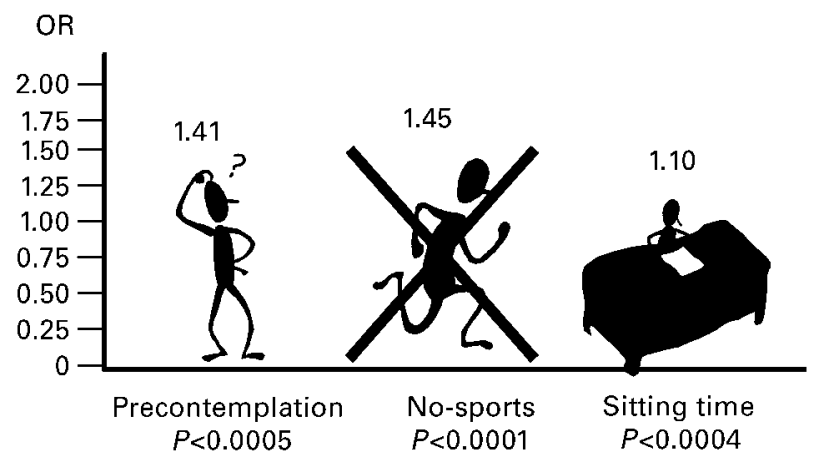

Fig. 4 Odds ratios (OR) of precontemplation, no physical activity and sitting time (hours per week) for obesity $\left(\mathrm{BMl} \geqslant 30 \mathrm{~kg} \mathrm{~m}^{-2}\right.$ ) versus normal or underweight individuals $\left(\mathrm{BMI}<25 \mathrm{~kg} \mathrm{~m}^{-2}\right.$ ) in Europe

\section{Discussion}

This pan-EU survey reflected that more than half of the EU subjects are at inappropriate weights for their heights. These percentages giving BMI based on selfreported heights and weights have been corroborated by BMI derived from measured heights and weights in two member states (Italy and Sweden) ${ }^{17}$. It is interesting to note that BMI categories are basically homogeneous across countries, in spite of all the differences in lifestyles and dietary habits, which suggests that obesity is a result of several determinants and that any strategy to reduce obesity will have similar basic targets, although in each country the guidelines may differ depending on attitudes and beliefs ${ }^{12}$.

Wide variation between the attitudes of health professionals, consumer organizations, the food industry and the media ${ }^{22}$ have been reported. Their messages are often controversial and contradictory and need to be reinforced with reliable and global epidemiological surveys taking into consideration societal issues such as education, socioeconomic status and environmental aspects, which may help to identify particular groups or populations more 
vulnerable to the obesity 'epidemic'. A successful health campaign relies on adequate duration and persistency, a staged approach, some legislative and education actions as well as a concerted action by consumers, community, industry and governments ${ }^{7}$.

Some comprehensive data on the prevalence of obesity in Europe comes from the WHO-Monica study $^{23}$, which reveal that the age-standardized average prevalence of obesity was lower in men than in women. Furthermore, trends in obesity in Europe indicate an increasing rate of this disorder to values/ proportions between $10 \%$ and $40 \%$ in the last decade $^{24,25}$. However, subgroup analysis by sex, age and education yielded some differences between countries, although in general a stronger increase in obesity prevalence was found in those with a low educational level as compared with those with a high education level in such a way that an inverse association was obtained from both women and men between BMI and educational level ${ }^{26}$. Furthermore, obesity in adolescents and young adults (16-24 years) has been found to correlate with objective indicators such as income, education and poverty rate ${ }^{27}$. Gender differences in adiposity and obesity prevalence may be a consequence of evolution ${ }^{28}$.

Culture concerns the patterns of behaviour and belief characteristics of a society, which affects both diet and exercise attitudes, as well as the social epidemiological incidence and interpretation of obesity $^{29}$. Obesity is more common in certain socioeconomic systems rather than in societies located in particular geographic zones, indicating that culture plays a central role in obesity ${ }^{30}$. Interestingly, there is a higher prevalence of obesity among southern populations than northern groups within the same country and a higher risk of obesity in rural than urban dwellers, which may reflect different regional levels of socioeconomic development ${ }^{7}$. The information available concerning different ethnic groups reveals that cultural forces may be involved in addition to the genetic background ${ }^{31}$, since when adjusted for health status variables, socioeconomic status and country of birth (ethnicity) are two reported independent factors influencing BMI in both sexes ${ }^{32}$.

Education, gender and socioeconomic status are closely intertwined $^{28}$. Thus, a number of studies have found that societies in the process of modernization have rapid increases in the prevalence of obesity ${ }^{7}$. The association of obesity and social class have received substantial attention. One study shows that in heterogeneous and affluent societies there is a strong inverse correlation of social class and obesity ${ }^{33}$. Socioeconomic status has been suggested as a risk factor, which may be affected by nutritional knowledge, access to resources, the media, etc. as well as by psychological stress ${ }^{34}$. The appropriateness of using social class in the EU sample maybe questioned as socioeconomic status is defined by different criteria in several countries of the EU and education has been used as a surrogate for socioeconomical status ${ }^{17}$.

In the UK, a tendency to increasing mean BMI between 1987 and 1991 has been observed in all social classes $^{9}$; the relationship between BMI and social class varied with gender. Thus, BMI tends to be higher in women in manual classes, while in men there is no clear relationship. Furthermore, an association between BMI and educational levels has been obtained with people in low levels of educational qualification having higher average values of $\mathrm{BMI}^{5,26}$, as occurs in the current survey of a representative sample of EU adults.

Marital status has also been shown to be associated with obesity ${ }^{35,36}$. Moreover, US women at greatest risk of weight gain are those with an education below college level, newly weds and those with a very low family income ${ }^{37}$, while marital status did not have significant effects on obesity among younger women ${ }^{38}$. On the other hand, the amount of weight gain associated with parity was greater in married than unmarried women, and less in those who were active outside of recreation versus those who were less active $^{39}$. All these observations are in good agreement with the results obtained in this EU study.

Smoking behaviour, too, has been associated with body weight gain ${ }^{40}$. Cigarette smoking tends to keep people slimmer than they would otherwise be by suppressing appetite and stimulating the body's metabolic rate ${ }^{41}$. Thus, epidemiological studies concerning obesity which do not take account of smoking behaviour may not reflect the risk associated with being overweight, because overweight non-smokers survive longer than thin smokers 9 . Our findings confirm that smoking cigarettes is associated with a lower BMI.

A community-based national epidemiological household survey conducted between 1990 and 1993 estimated the prevalence of obesity in Saudi Arabia ${ }^{42}$, and examined its association with the sociodemographic characteristics of the adult population. The multiple logistic regression analysis showed that age, residential area, region, income, gender and education were statistically significant predictors of obesity. The prevalence of obesity was higher in females than males, lower in subjects living in rural areas with traditional lifestyles than those in more urbanized environments, and increased with increasing age. The observed prevalence and pattern of obesity with age and gender in this study was similar to those observed in other western nations ${ }^{5,26}$.

Within areas of similar economic development, regional consumption of fat and prevalence of obesity have not been positively correlated. Thus, within the USA a substantial decline in fat and calorie intake and 
frequent use of low-calorie food products have been associated with a paradoxical massive increase in obesity rates ${ }^{43}$. These diverging trends may suggest that there has been a dramatic decrease in total physical-activity-related energy expenditure ${ }^{44}$. In fact, the growing increase in the number of obese people in Europe appears to be associated with the accompanying increase in sedentarism ${ }^{25}$.

Furthermore, an analysis of time-budget surveys reveals that the time required for earning a living and domestic work has declined appreciably over recent decades ${ }^{45}$. This negative trend is associated with a substantial decline in the energy spent on these activities. The review of a large dataset on energy expenditure under free-living conditions indicates that, despite their phenomenally diverse rates of obesity, there is no systematic difference between developed and developing societies. Multivariate regression analysis of BMI on physical activity level reveals a weak, but statistically significant, inverse relationship in men but not in women.

Physical activity assessment has been often carried out through questionnaires and interviews as well as through activity monitors; however, obtaining valid and appropriate measurements of physical activity remains a challenging task ${ }^{14}$. Epidemiological studies have typically used subjective measures to assess physical activity in populations-obtaining information about the period of time dedicated to sports or to watching TV or whether the subject has considered the possibility of doing some physical activity (precontemplation) - because of non-reactiveness, practicality, applicability and accuracy of these tests ${ }^{20,46,47}$.

Using such methodological approaches, a prospective 10-year follow-up study in three municipalities in Finland showed that men and women with no regular weekly activity had an OR of 2.59 and 2.67, respectively, for clinically significant body mass gain in comparison with the most active, after an adjustment for the potential confounders ${ }^{48}$. Other results support this hypothesis, since lack of physical activity and low physical fitness appear as important contributing factors in the development and/or maintenance of obesity in African-American girls ${ }^{49}$. On the other hand, obese subjects reported physical impairment and reduced mobility more often ${ }^{50}$, while only $10 \%$ of subjects in an obese group and $24.4 \%$ of subjects in a non-obese group selected a moderate or higher level as indicative of the intensity of their daily physical activity ${ }^{51}$. Genetic factors may modify the effects of physical activity on weight change and it has been suggested that a sedentary lifestyle may have an obesity-promoting effect in men with a genetic predisposition $^{52}$. Although physical activity levels are highly variable across different countries, beliefs in their health benefits are associated with the desire for losing weight ${ }^{53}$ and also with the idea of staying healthy, to be fit or to relieve stress. In general, the information obtained from this pan-EU survey is in accordance with the existing evidence ${ }^{54}$ that preventing diseases and quality of life are considered as the main benefits of a healthy lifestyle concerning dietary and physical activity habits.

Dietary and exercise interventions targeted to reduce obesity may have long-term effects on behavioural and public health models ${ }^{55}$. Existing data suggest that discouraging physical inactivity and decreasing the time in sedentary behaviours should be considered as potential strategies in obesity prevention programmes ${ }^{13,46}$. However, the contents of health promotion activities could vary according to the differences related to age, gender and other socioeconomic and cultural variables of the targeted populations ${ }^{51,56}$. In any case, prescribing exercise for health by physicians and other health professionals may be beneficial in primary care ${ }^{57,58}$, while scientists and public health officials need to turn attention to public policy and legislative initiatives to restructure social environments to encourage more physical activity and discourage sedentary and other unhealthy habits ${ }^{2,7,59-61}$.

This survey confirms that one priority area for health intervention aimed at preventing the development of obesity should be increasing levels of physical activity, although the approach will depend on the characteristics of the population, especially with respect to educational aspects, while prevention of obesity in the not yet overweight or obese individuals appears a very important goal in stemming the rise in obesity rates.

\section{Acknowledgements}

The scientific and financial support from the IEFS (Dublin) and Directorate General (DGV) from the EU are gratefully recognized.

\section{References}

1 Steptoe A, Wardle J. What the experts think: a European study of expert opinion about the influence of lifestyle on health. Eur. J. Epidemiol. 1994; 10: 195-203.

2 Ashenden R, Silagy C, Weller D. A systematic review of the effectiveness of promoting lifestyle change in general practice. Fam. Pract. 1997; 14: 160-76.

3 Blair SN, Horton E, Leon AS, et al. Physical activity, nutrition, and chronic disease. Med. Sci. Sports Exerc. 1996; 28: $335-49$

4 Martínez JA. Nutrición, Metabolismo y Obesidad: Avances y Nuevas Perspectivas. San Sebastián: Universidad del País Vasco, 1996.

5 Bray GA, Bouchard C, James WPT. Handbook of Obesity. New York: Marcel Dekker, 1998.

6 Hill JO, Peters JC. Environmental contributions to the obesity epidemic. Science 1998; 280: 1371-4.

7 World Health Organization. Obesity. Preventing and Managing the Global Epidemic. Geneva: World Health Organization, 1998. 
8 Drenoski A, Potkin BM. The nutrition transition: trends in the global diet. Nutr. Rev. 1997; 55: 31-43.

9 Department of Health. Obesity: a Report from the Nutrition and Physical Activity Task Forces. Reversing the Increasing Problem of Obesity. London: HMSO, 1996.

10 Gill TP. Key issues in the prevention of obesity. Br. Med. Bull. 1997; 53: 359-88.

11 Jeffery RW. Community programs for obesity prevention. Obes. Res. 1995; 3: S203-8.

12 Cowburn G, Hillsdwon M, Hankey CR. Obesity management by life-style strategies. Br. Med. Bull. 1997; 53: $389-408$

13 Coakley EH, Rimm EB, Colditz G, Kawachi I, Willett W. Predictors of weight change in men: results from the health professionals follow-up study. Int. J. Obes. Relat. Metab. Disord. 1998; 22: 89-96.

14 Williamson DA, O'Neill PM. Behavioural and psychological correlates of obesity. In: Bray GA, Bouchard C, James WPT, eds. Handbook of Obesity. New York: Marcel Dekker, 1998; 129-42.

15 Kolotkin RL, Head S, Hamilton M. Assessing the impact of weight on quality of life. Obes. Res. 1995; 3: 49-56.

16 Kearney M, Kearney JM, Gibney MJ. Methods used to conduct surveys on consumer attitudes to food, nutrition and health. Eur. J. Clin. Nutr. 1997; 59: 53-7.

17 IEFS. A pan EU Survey on Consumer Attitudes to Physical Activity, Body Weight and Health. Luxembourg: Directorate General, European Union, 1998.

18 ICC/ESOMAR. Code of Marketing and Social Research Practice. Amsterdam: ICC, 1990.

19 Prochaska JD, Norcross JC, Fowler JL. Attendance and outcome at work control program: processes and stages of change as process and predictor variables. Addict. Bebav. 1992; 17: 35-45.

20 Kriska AM, Caspersen CJ. Introduction to a collection of physical activity questionnaires. Med. Sci. Sports Exerc. 1997; 29: $55-9$.

21 Martínez-González MA. Bioestadística. Pamplona: New Book Ed., 1997.

22 Almeida MDV, Grace P, Lappalainen R, et al. Sources used and trusted by nationally representative adults in the EU for information on healthy eating. Eur. J. Clin. Nutr. 1997; 51: S16-23.

23 WHO-Monica Project. Risk factors. Int. J. Epidemiol. 1989; 18: $S 46-56$

24 Seidell JC. Obesity in Europe-scaling a epidemic. Int. J. Obes. 1995; 19: S1-4.

25 Prentice AM, Jebb SA. Obesity in Britain: gluttony or sloth? BMJ 1995; 311: 437-9.

26 Seidell JC, Rissanen AM. Time trends in the world wide prevalence of obesity. In: Bray GA, Bouchard C, James WPT, eds. Handbook of Obesity. New York: Marcel Dekker, 1998, 79-92.

27 Gortmaker SL, Must A, Perrin JM, Sobal AM, Dietz WH. Social and economic consequences of overweight in adolescents and young adulthood. N. Engl. J. Med. 1993; 329: 1008-12.

28 Brown PJ, Bentley-Counder VK. Culture, evolution, obesity. In: Bray GA, Bouchard C, James WPT, eds. Handbook of Obesity. New York: Marcel Dekker, 1998; 143-56.

29 Brown PJ. Culture and the evolution of obesity. Hum. Nat. 1991; 2: 31-57.

30 Baba S, Zimmet P. World Data Book on Obesity. New York: Elsevier Science, 1990.

31 Sorenssen TI, Holst C, Stunkard AJ. Adoption study of environmental modifications of the genetic influences on obesity. Int. J. Obes. Relat. Metab. Disord. 1998; 22: 73-81.

32 Sundquist J, Johansson SE. The influence of socio-economic status, ethnicity and lifestyle on body mass index in a longitudinal study. Int. J. Epidemiol. 1998; 27: 57-63.
33 Goldblatt PB, Moore ME, Stunkard AJ. Social factors in obesity. JAMA 1995; 191: 1039-44.

34 Wamala SP, Wolk A, Orth-Gomer K. Determinants of obesity in relation to socio-economic status among middle-aged Swedish women. Prev. Med. 1997; 26: 734-44.

35 Sobal J, Rauschenbach BS, Frongillo EA Jr. Marital status, fatness and obesity. Soc. Sci. Med. 1992; 35: 915-23.

36 Friedman EH. Fatness and obesity among married men at lower risk for mortality and morbidity may be due to less physiological arousal. Soc. Sci. Med. 1993; 36: 583.

37 Kahn HS, Williamson DF, Stevens JA. Race and weight change in US women: the roles of socio-economic and marital status. Am. J. Public Health 1991; 81: 319-23.

38 Herman AA, Yu KF. Adolescent age at first pregnancy and subsequent obesity. Paediatr. Perinat. Epidemiol. 1997; 11: 130-41.

39 Wolfe WS, Sobal J, Olson CM, Frongillo EA Jr. Parityassociated body weight: modification by socio-demographic and behavioural factors. Obes. Res. 1997; 5: 131-41.

40 Williamson DF. Smoking cessation and severity of weight gain in a national cohort. N. Engl. J. Med. 1991; 324: 739-45.

41 Grumberg NE. Biological factors in the relationship between tobacco use and body weight. Adv. Behav. Med. 1986; 2 97-129.

42 Al-Nuaim AA, Bamgboye EA, Al-Rubeaan KA, Al-Mazrou Y. Overweight and obesity in Saudi Arabian adult population: role of socio-demographic variables. J. Comm. Health 1997; 22: $211-23$

43 Willett WC. Is dietary fat a major determinant of body fat? Am.J. Clin. Nutr. 1998; 67: S556-62.

44 Heini AF, Weinsier RL. Divergent trends in obesity and fat intake patterns: the American paradox. Am. J. Med. 1997; 192: 259-64.

45 Ferro-Luzzi A, Martino L. Obesity and physical activity. Ciba Found. Symp. 1996; 201: 207-27.

46 Fitzgerald SJ, Kriska AM, Pereira MA, De-Courten MP. Associations among physical activity, television watching and obesity in adult Pima Indians. Med. Sci. Sports Exerc. 1997; 29: 910-15.

47 Prochaska JD, Velicer WF, Rossi JS. Stages of change and decisional balance for 12 problem behaviours. Health Psychol. 1994; 13: 39-46.

48 Haapanen N, Miilunpalo S, Pasanen M, Oja P, Vouri I. Association between leisure time physical activity and 10 year body mass change among working-aged men and women. Int. J. Obes. Relat. Metab. Disord. 1997; 21 288-96.

49 Ward DS, Trost SG, Felton G, et al. Physical activity and physical fitness in African American girls with and without obesity. Obes. Res. 1997; 4: 572-7.

50 Wolk A, Rossner S. Obesity and self-perceived health in Sweden. Int. J. Obes. Relat. Metab. Disord. 1996; 20: 369-72.

51 Talvi AI, Jarvisalo JO, Knuts LR, Kaitaniemi PR. Life-style related health promotion needs in oil refinery employees. Occup. Med. 1998; 48: 45-53.

52 Heitmann BL, Kaprio J, Harris JR, Rissanen A, Korkeila M, Koskenvou M. Are genetic determinants of weight gain modified by leisure time physical activity? A prospective study of Finnish twins. Am. J. Clin. Nutr. 1997; 66: 672-8.

53 Steptoe A, Wardle J, Fuller R, et al. Leisure-time physical exercise: prevalence, attitudinal correlates, and behavioural correlates among young Europeans from 21 countries. Prev. Med. 1997; 26: 845-54

54 Zunft HJF, Friebe D, Seppelt B, et al. Perceived benefits of healthy eating among a nationally-representative sample of adults in the European Union. Eur. J. Clin. Nutr. 1997; 51: S41-6. 
55 Johnson WG, Hinkle LK, Carr RE, et al. Dietary and exercise interventions for juvenile obesity: long-term effect of behavioural and public health models. Obes. Res. 1997; 5: 257-61.

56 Stafford M, Hemingway H, Marmot M. Current obesity, steady weight change and weight fluctuation as predictors of physical functioning in middle aged office workers: the Whitehall II study. Int. J. Obes. Relat. Metab. Disord. 1998; 22: 23-31.

57 Cade J, O'Donnell S. Management of obesity. Knowledge attitudes and current practice of general practitioners. Br.J. General Pract. 1991; 41: 147-50.
58 Will PM, Demko TM, George DL. Prescribing exercise for health: a simple framework for primary care. Am. Fam. Physician 1996; 53: 579-85.

59 Blair SN, Nooth M, Gyarfas I, et al. Development of public policy and physical activity initiatives internationally. Sports Med. 1996; 21: 157-63.

60 Hendricks KM, Herbold NH. Diet, activity, and other healthrelated behaviours in college-age women. Nutr. Rev. 1998; 56: $65-75$.

61 King AC. Community intervention for promotion of physical and fitness. Exerc. Sport Sci. Rev. 1991; 91: 211-59. 